\title{
Thromboprophylaxis After Minimally Invasive Total Knee Arthroplasty: A Comparison of Rivaroxaban and Enoxaparin
}

\author{
Shih-Hsiang Yen, Po-Chun Lin, Feng-Chih Kuo, Jun-Wen Wang
}

Background: Total knee arthroplasty (TKA) carries a substantial rate of venous thromboembolism (VTE). The blood-saving of effect of tranexamic acid (TEA) in TKA using enoxaparin for thromboprophylaxis has been well known. However, the routine use of chemoprophylaxis in TKA remains controversial because of postoperative bleeding complications. Therefore, the purpose of this study was to retrospectively compare the incidence of VTE, and postoperative blood loss and wound-related complications in minimally invasive (MIS)-TKA patients who received rivaroxaban or enoxaparin prophylaxis.

Methods: A total of 113 patients who underwent primary unilateral MIS-TKA between 2009 and 2012 were studied. Of these, 61 patients (study group) received rivaroxaban prophylaxis between 2011 and 2012 and a control group of 52 patients received enoxaparin prophylaxis between 2009 and 2010. All patients received one intraoperative injection of TEA $(10 \mathrm{mg} / \mathrm{kg})$. We compared the changes in hemoglobin $(\mathrm{Hb})$ level, postoperative drainage amount, total blood loss, transfusion rate, and incidence of postoperative wound complications and VTE between the two groups.

Results: $\quad$ No differences in postoperative $\mathrm{Hb}$ levels, blood drainage amount, total blood loss, and transfusion rate were observed between the two groups. No deep-vein throm-

\begin{abstract}
At a Glance Commentary
Scientific background of the subject

Venous thromboembolism (VTE) is a common complication after total knee arthroplasty (TKA). There are many anticoagulants used in VTE prophylaxis. Rivaroxaban is convenient to use and its efficacy has been reported, but the increased risk of bleeding complications has also been concerned. The purpose of this study was to retrospectively compare the efficacy, postoperative blood loss and complications in TKA patients who received rivaroxaban or enoxaparin prophylaxis.
\end{abstract}

\section{What this study adds to the field}

Our study demonstrated low rate of VTE in TKA patients who received rivaroxaban or enoxaparin. No increased perioperative bleeding or postoperative wound-related complications were observed in the rivaroxaban group compared with the enoxaparin group. Our study showed the efficacy and safety of the use of rivaroxaban in clinical practice bosis of the leg or pulmonary embolism was noted in both groups. There were no major wound complications including hematoma and infection requiring surgical intervention for open irrigation or debridement.

Conclusions: Our retrospective study demonstrated a low rate of VTE in MIS-TKA patients who received rivaroxaban or enoxaparin when TEA was used for bleeding prophylaxis. No increased perioperative bleeding or postoperative wound-related complications were observed in the rivaroxaban group compared with the enoxaparin group.

(Biomed J 2014;37:199-204)

Key words: enoxaparin, minimally invasive total knee arthroplasty, rivaroxaban, thromboprophylaxis, tranexamic acid

From the Department of Orthopaedic Surgery, Kaohsiung Chang Gung Memorial Hospital, Chang Gung University College of Medicine, Kaohsiung, Taiwan

Received: Nov. 27, 2012; Accepted: Jun. 28, 2013

Correspondence to: Dr. Jun-Wen Wang, Department of Orthopedic Surgery, Kaohsiung Chang Gung Memorial Hospital. 123, Dapi Rd., Niaosong Dist., Kaohsiung City 833, Taiwan (R.O.C.). Tel.: 886-7-7317123 ext. 8003; Fax: 886-7-7354309; E-mail: wangjw@adm.cgmh.org.tw

DOI: $10.4103 / 2319-4170.125627$ 


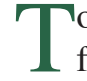
otal knee arthroplasty (TKA) is an effective procedure for end-stage arthritis of the knee (including osteoarthritis, rheumatoid arthritis, and posttraumatic arthritis) in terms of pain relief and functional recovery. ${ }^{[1,2]}$ However, venous thromboembolism (VTE) remains a common complication after TKA. The incidence of total deep-vein thrombosis (DVT) ranges from 1 to $84 \%$ (median $34 \%$ ). Total pulmonary embolism (PE) after TKA occurs between $0 \%$ and $12 \%$ (median $4.6 \%$ ), with fatal PE occurring in $0-1.1 \%$ (median $0.22 \%$ ). ${ }^{[3]}$ Therefore, some types of thromboprophylaxis are recommended for TKA.

In recent years, there have been more effective and practical methods for thromboprophylaxis in joint replacement surgery. Low-molecular-weight heparins (LMWHs) are the standard of care for thromboprophylaxis in hip and knee replacements. ${ }^{[4,5]}$ However, LMWH needs hospitalization for daily subcutaneous injection, which is not convenient for short hospital stay in contemporary TKA. Rivaroxaban (Xarelto; Bayer Schering Pharma AG, Wuppertal, Germany) is a novel, oral, direct factor Xa inhibitor, which has been licensed for thromboprophylaxis after total knee and hip replacement surgery. The advantages of rivaroxaban include oral administration, no need to monitor blood levels, and no dosing adjustments. Its efficacy in preventing VTE following hip and knee replacements has been extensively investigated and the results showed that rivaroxaban $10 \mathrm{mg}$ once daily was more effective than enoxaparin $40 \mathrm{mg}$ once daily. ${ }^{[6,7]}$ Despite the clinical efficacy of rivaroxaban in VTE prophylaxis, the increased risk of bleeding complications is of great concern. A higher reoperation rate regarding wound complications in rivaroxaban group $(2.94 \%)$ compared with tinzaparin group (1.8\%) within 30 days of hip or knee replacement was reported recently. ${ }^{[8]}$ This event is associated with a significantly increased risk for the development of deep infection or subsequent major surgery. ${ }^{[9]}$

Tranexamic acid (TEA), an inhibitor of fibrinolysis, is effective in reducing perioperative blood loss and the need for transfusion after conventional ${ }^{[10,11]}$ as well as minimally invasive TKA (MIS-TKA). ${ }^{[12]}$ Several previous reports have calculated the blood-saving effect of TEA is TKA, but all of these studies were use of the anticoagulants other than rivaroxaban for thromboprophylaxis. ${ }^{[12,13]}$

The purpose of this study was to retrospectively compare the incidence of VTE in one group of patients using rivaroxaban with another group of patients using enoxaparin after MIS-TKA and to see whether there is increased total blood loss and wound-related complications in the rivaroxaban group.

\section{METHODS}

A cohort study was conducted on consecutive series of 96 patients receiving rivaroxaban prophylaxis after primary unilateral MIS-TKA between September 2011 and February 2012. A control group was indentified including 52 patients receiving enoxaparin prophylaxis after MIS-TKA during the period between July 2009 and August 2010. We excluded the patients who had past history of previous surgery on the operated knee, thrombocytopenia, anemia [hemoglobin $(\mathrm{Hb})$ $<10 \mathrm{~g} / \mathrm{dl}$ ], lifelong warfarin therapy, coagulopathy, VTE, or major comorbidities (ischemic heart disease, cerebrovascular accident, liver cirrhosis, end-stage renal disease). Finally, 61 patients were included in the study group. The control group patients were the same as in our previous prospective randomized study. ${ }^{[13]}$ Therefore, they had been already selected according to the aforementioned exclusion criteria.

All patients were asked to abstain from taking antiplatelet drugs for thromboprophylaxis 7 days before surgery. All patients received one intraoperative injection of TEA $(10 \mathrm{mg} / \mathrm{kg})$ by slow intravenous infusion before deflation of the tourniquet after MIS-TKA for bleeding prophylaxis. In the control group, we used enoxaparin (Clexane; GlaxoSmithKline, Brentford, United Kingdom) subcutaneously for VTE prophylaxis, which was started on postoperative day (POD) 1, at a dose of $20 \mathrm{mg}$ every $12 \mathrm{~h}$ until discharge. After that, patients were given indomethacin orally or as suppository for at least 4 weeks, as we previously reported for VTE prophylaxis in TKA. ${ }^{[14]}$ In the study group, we used rivaroxaban for VTE prophylaxis starting on POD 1, at a dose of $10 \mathrm{mg}$ daily for 2 weeks. This study was approved by the Institutional Review Board of Chang Gung Memorial Hospital.

Preoperative data including $\mathrm{Hb}$ levels, hematocrit (Hct) levels, prothrombin time (PT), activated partial thromboplastin time (APTT), and platelet count were collected. The demographics of the patients including age, gender, body mass index (BMI), and American Society of Anesthesiologists (ASA) risk were recorded [Table 1].

All operations were performed or supervised by the same surgeon (JWW) using the mini-midvastus approach for MIS-TKA, according to the procedure of Haas et al..$^{[15]}$ All patients received general anesthesia. A tourniquet was inflated to a pressure of $300 \mathrm{mmHg}$ before the incision. All TKAs were unilateral and were cemented using the same prosthesis (NexGen, Legacy Posterior Stabilized Prosthesis; Zimmer, Warsaw, IN, USA). An intramedullary alignment rod was used for femoral preparation and an extramedullary guide system for tibial preparation. The femoral canal was routinely plugged with bone. The tourniquet was not released until skin closure and the application of a compressive dressing. Two intra-articular drains were used with open drainage (i.e., without compression of the bag) during the first $12 \mathrm{~h}$ after surgery. The vacuum bag was then fully compressed to create a negative pressure. The drains were removed on the second POD no matter what the drain output was. The postoperative rehabilitation program included con- 
Table 1: Clinical model for predicting pretest probability for deep-vein thrombosis (Wells et al. ${ }^{[7]}$ )

\begin{tabular}{lc}
\hline Clinical feature & Score \\
\hline $\begin{array}{l}\text { Active cancer (treatment ongoing or within previous } \\
6 \text { months or palliative) }\end{array}$ & 1 \\
$\begin{array}{l}\text { Paralysis, paresis, or recent plaster immobilization of the } \\
\text { lower extremities }\end{array}$ & 1 \\
$\begin{array}{l}\text { Recently bedridden for more than } 3 \text { days or the patient } \\
\text { underwent a major surgery in recent } 4 \text { weeks }\end{array}$ & 1 \\
$\begin{array}{l}\text { Localized tenderness along the distribution of the deep } \\
\text { venous system }\end{array}$ & 1 \\
$\begin{array}{l}\text { Entire leg swollen } \\
\text { Calf swelling by more than } 3 \text { cm when compared with the } \\
\text { asymptomatic leg (measured } 10 \text { cm below tibial tuberosity) }\end{array}$ & 1 \\
$\begin{array}{l}\text { Pitting edema (greater in the symptomatic leg) } \\
\text { Collateral superficial veins (non-varicose) }\end{array}$ & 1 \\
$\begin{array}{l}\text { Alternative diagnosis as likely or greater than that of } \\
\text { deep-vein thrombosis }\end{array}$ & 1 \\
\hline $\begin{array}{l}\text { In patients with symptoms in both legs, the more symptomatic leg is } \\
\text { used }\end{array}$ & -2
\end{tabular}

tinuous passive motion of the knee and muscle strengthening exercise after returning to the ward, and routine mobilization on the first POD. The criteria for discharge were a range of movement of the knee $>90^{\circ}$, a clean wound without discharge, and the ability to walk with walker support.

We checked the Hb level on POD 1 and 4. We assumed that the blood volume was normalized on POD 4. Total $\mathrm{Hb}$ loss was calculated by subtracting the $\mathrm{Hb}$ level on POD 4 from the preoperative level. The total blood loss was calculated from the maximum $\mathrm{Hb}$ loss and the amount of blood transfusion. According to Nadler et al. ${ }^{[16]}$ the formula can be shown as follows: total blood loss $=$ [total blood volume $\times$ (change in $\mathrm{Hb}$ level/mean $\mathrm{Hb}$ )] + volume transfused. Blood loss was calculated by subtracting the amount of drainage from the total blood loss. The trigger for allogenic blood transfusion was set at an $\mathrm{Hb}$ level of $8 \mathrm{~g} / \mathrm{dl}$ in healthy patients or between $8 \mathrm{~g} / \mathrm{dl}$ and $9 \mathrm{~g} / \mathrm{dl}$ in patients with symptoms of acute anemia. ${ }^{[12]}$

All these patients had completed follow-up of at least 90 days. We recorded wound condition including prolonged drainage, ecchymosis or hematomas, wound-related complications such as infections and/or major hematoma requiring open irrigation or debridement at the operating room (OR) and major bleeding events (cerebrovascular event or gastrointestinal hemorrhage), and the 90-day rates of symptomatic DVT (proximal or distal), symptomatic PE, and all-cause inpatient mortality after MIS-TKA. The presence of DVT was evaluated according to the clinical model of pretest probability for DVT designed by Wells et al., ${ }^{[17]}$ [Table 1]. An antegrade venography of both legs was arranged in patients with high (3 or more) pretest probability. PE should be suspected in all patients who present with new or worsening dyspnea, chest pain, or sustained hypotension without an alternative obvious cause. A computed tomography of the chest wound was performed to confirm the diagnosis of PE. ${ }^{[18]}$

\section{Statistical analysis}

We compared the differences in age, BMI, wound length, length of stay, preoperative and postoperative $\mathrm{Hb}$ and Hct levels, platelet count, International Normalized Ratio (INR) PT, APTT, tube drainage, and total blood loss between the groups using independent $t$-test. We compared the differences in anesthesia type, ASA, preoperative co-morbidity and postoperative complications, and the number of patients who required blood transfusion using the Chi-square test or Fisher's exact test, as appropriate. All the statistical comparisons were made using the Statistical Package for Social Science (SPSS) software (version 16; SPSS Inc., Chicago, IL, USA).

\section{RESULTS}

A total of 113 patients (61 in the study group and 52 in the control group) were included in the statistical analysis. The minimum follow-up period was 12 weeks (range 12-48 weeks). The general characteristics of both groups including gender, age, BMI, ASA risk, Hb level, Hct level, PT INR, APTT INR, and platelet count were similar [Table 2].

The wound length was shorter in the study group $(9.16 \mathrm{~cm})$ than in the control group $(10.3 \mathrm{~cm})(p<0.001)$. The hospital stay was slightly longer in the study group than in the control group (5.7 days vs. 5.3 days) $(p=0.015)$. The Hb level on POD 1 was similar between the two groups $(11.2 \mathrm{~g} / \mathrm{dl}$ vs. $11.6 \mathrm{~g} / \mathrm{dl})$. The $\mathrm{Hb}$ level on POD 4 in the study group was $9.46 \mathrm{~g} / \mathrm{dl}$, which was similar to $9.78 \mathrm{~g} / \mathrm{dl}$ observed in the control group. The total drainage accumulated in the hemovac was $497 \pm 189 \mathrm{ml}$ in the study group, which was also similar to $543 \pm 162 \mathrm{ml}$ found in the control group ( $p=0.174)$. The total blood loss was $1085 \pm 260 \mathrm{ml}$ in the study group and $1035 \pm 259 \mathrm{ml}$ in the control group, indicating that the difference between the groups was not significant $(p=0.314)$. Four patients $(6.6 \%)$ in the study group and two patients $(3.8 \%)$ in the control group required transfusion $(p=0.526)$. The mean units of blood transfused were $0.16 \pm 0.66 \mathrm{U}$ in the study group and $0.07 \pm 0.39 \mathrm{U}$ in the control group $(p=0.407)$. Again, the difference was not significant [Table 3].

No major wound complications that required open irrigation or debridement at the OR, or 90-day postoperative mortality of any cause was encountered. Some patients experienced ecchymosis around thigh, knee, and leg, which was more common in the study group $(41 \%)$ than in the control group $(14 \%)(p=0.001)$. Other wound complications including hematoma, bullae formation, and superficial skin 
Table 2: Characteristics of 113 patients with total knee arthroplasty

\begin{tabular}{|c|c|c|c|}
\hline Characteristics & Study (rivaroxaban) group $(n=61)$ & Control (enoxaparin) group $(n=52)$ & $p$ \\
\hline Age (years) & $69.9 \pm 7.7(56,85)$ & $70.6 \pm 8.0(55,93)$ & 0.638 \\
\hline Women $(\%)$ & $51(83.7)$ & $43(82.7)$ & 0.898 \\
\hline BMI $\left(\mathrm{kg} / \mathrm{m}^{2}\right)$ & $27.6 \pm 4.22(20.1,38.4)$ & $28.0 \pm 3.84(22.2,39.5)$ & 0.602 \\
\hline Preoperative $\mathrm{Hb}(\mathrm{g} / \mathrm{dl})$ & $13.0 \pm 1.02(11.4,17.5)$ & $13.4 \pm 1.18(11.4,16.9)$ & 0.070 \\
\hline Preoperative Hct & $39.8 \pm 2.60(36.3,50.9)$ & $40.9 \pm 3.34(34.8,49.9)$ & 0.065 \\
\hline PT INR & $0.98 \pm 0.026(0.91,1.02)$ & $0.96 \pm 0.033(0.89,1.04)$ & 0.121 \\
\hline APTT INR & $0.95 \pm 0.054(0.84,1.10)$ & $0.93 \pm 0.065(0.81,1.10)$ & 0.055 \\
\hline Platelet count $\left(10^{3} / \mathrm{uL}\right)$ & $233 \pm 42(163,374)$ & $247 \pm 64(172,554)$ & 0.169 \\
\hline \multicolumn{4}{|l|}{ ASA } \\
\hline 1 & $4 / 61(6.6 \%)$ & $0 / 52(0 \%)$ & 0.062 \\
\hline 2 & $48 / 61(78.7 \%)$ & $38 / 52(73.1 \%)$ & \\
\hline 3 & $9 / 61(14.8 \%)$ & $14 / 52(26.8 \%)$ & \\
\hline
\end{tabular}

Numbers in parentheses are standard deviation and ranges. Abbreviations: APTT: Active partial thromboplastin time; ASA: American society of anesthesiologists; BMI: Body mass index; INR: International normalized ratio; PT: Prothrombin time; Hb: Hemoglobin

Table 3: Postoperative data of all patients

\begin{tabular}{|c|c|c|c|}
\hline & Study (rivaroxaban) group $(n=61)$ & Control (enoxaparin) group $(n=52)$ & $p$ \\
\hline Wound length $(\mathrm{cm})$ & $9.16 \pm 0.85(7.0,11.0)$ & $10.3 \pm 1.08(8.5,13.0)$ & $<0.001$ \\
\hline Hospital stay (days) & $5.7 \pm 1.07(5,11)$ & $5.3 \pm 0.61(5,7)$ & 0.015 \\
\hline \multicolumn{4}{|l|}{ Postoperative $\mathrm{Hb}(\mathrm{g} / \mathrm{dl})$} \\
\hline POD 1 & $11.2 \pm 1.05(9.7,14.8)$ & $11.6 \pm 1.25(9.0,15.0)$ & 0.065 \\
\hline POD 4 & $9.46 \pm 1.11(7.2,12.6)$ & $9.78 \pm 1.08(7.7,12.7)$ & 0.121 \\
\hline Blood transfusion required & $4 / 61(6.6 \%)$ & $2 / 52(3.8 \%)$ & 0.526 \\
\hline Units of blood transfusion & $0.16 \pm 0.66(0,4)$ & $0.07 \pm 0.39(0,2)$ & 0.407 \\
\hline Total drainage $(\mathrm{ml})$ & $497 \pm 189(125,930)$ & $543 \pm 162(195,835)$ & 0.174 \\
\hline Total blood loss (ml) & $1085 \pm 260(504,1785)$ & $1035 \pm 259(397,1934)$ & 0.314 \\
\hline
\end{tabular}

All data are presented as mean. Numbers in parentheses are standard deviation and range. Abbreviations: Hb: Hemoglobin; POD: Postoperative day

necrosis were similar between the two groups. Throughout the study, no other major complications such as massive gastrointestinal bleeding, cerebrovascular accident, deep infection, or periprosthetic fractures were found. There was no DVT or PE in both groups [Table 4].

\section{DISCUSSION}

The American College of Chest Physicians (ACCP) guidelines recommended thromboprophylaxis with LMWHs, vitamin $\mathrm{K}$ antagonists, or fondaparinux (injection form of factor Xa inhibitor) for at least 10 days in patients undergoing TKA. ${ }^{[19]}$ However, it is well understood that anticoagulants that reduce the incidence of DVT (chemoprophylaxis) are associated with increased risks of postoperative bleeding. ${ }^{[20,21]}$ The incidence of significant bleeding events is reported from 1.8 to $5.1 \%$, which may be underappreciated in the well-controlled reports. ${ }^{[22]}$ A study of physician compliance with guidelines for DVT prevention in hip and knee arthroplasty showed that full compliance with the guidelines in terms of type, duration, start time, and dose was achieved for $61 \%$ of TKA patients in the United States and $69 \%$ of TKA patients outside the United States ${ }^{[23]}$ The physician compliance rate was considered even lower in Asian patients. ${ }^{[24]}$
Table 4: Complications within 90 days postoperatively

\begin{tabular}{lccc}
\hline & $\begin{array}{c}\text { Study } \\
\text { (rivaroxaban) } \\
\text { group }(n=61)\end{array}$ & $\begin{array}{c}\text { Control } \\
\text { (enoxaparin) } \\
\text { group }(n=52)\end{array}$ & $p$ \\
\hline Ecchymosis & $25 / 61(41 \%)$ & $7 / 52(14 \%)$ & 0.001 \\
Hematoma & $1 / 61(1.6 \%)$ & $0 / 52(0 \%)$ & 0.358 \\
Bullae formation & $1 / 61(1.6 \%)$ & $2 / 52(3.8 \%)$ & 0.471 \\
Superficial skin necrosis & $0 / 61(0 \%)$ & $1 / 52(1.9 \%)$ & 0.281 \\
Superficial infection & $1 / 61(1.6 \%)$ & $0 / 52(0 \%)$ & 0.358 \\
Major bleedings & $0 / 61(0 \%)$ & $0 / 52(0 \%)$ & \\
Deep-vein thrombosis & $0 / 61(0 \%)$ & $0 / 52(0 \%)$ & \\
Pulmonary embolism & $0 / 61(0 \%)$ & $0 / 52(0 \%)$ & \\
Return to OR for debridement & $0 / 61(0 \%)$ & $0 / 52(0 \%)$ & \\
Mortality & $0 / 61(0 \%)$ & $0 / 52(0 \%)$ & \\
\hline
\end{tabular}

Abbreviation: OR: Operating room

Rivaroxaban, as compared with enoxaparin, has been shown to have superior efficacy as a thromboprophylaxis in hip and knee replacement surgeries by the REgulation of Coagulation in ORthopedic surgery to prevent Deep vein thrombosis and pulmonary embolism (RECORD) trials. ${ }^{[6,7]}$ However, concerning postoperative wound complications that were related to increased bleeding events, one of the authors of the RECORD4 paper did not recommend rivaroxaban to his 
patients. ${ }^{[25]}$ Two of our previous prospective clinical trials have shown that TEA was effective in reducing postoperative blood loss and the needs for transfusion in MIS-TKA patients. ${ }^{[12,13]}$ Those two trials used enoxaparin for thromboprophylaxis during hospitalization only, because it requires parenteral administration. Extended thromboprophylaxis after discharge from the hospital was conducted using indomethacin which we consider as inadequate according to the ACCP guidelines. ${ }^{[19]} \mathrm{We}$, therefore, started using rivaroxaban prophylaxis in 2011 after its approval as chemical thromboprophylaxis in hip and knee replacements in Taiwan.

Our results show that TEA at $10 \mathrm{mg} / \mathrm{kg}$ in one bolus injection has a similar effect on total blood loss and the need for transfusion after MIS-TKA as that of enoxaparin or rivaroxaban prophylaxis. Our previous prospective randomized trial of the use of TEA in MIS-TKA patients with enoxaparin prophylaxis showed that total blood loss in one injection $(10 \mathrm{mg} / \mathrm{kg}$ ) TEA group was $1035 \mathrm{ml}$, which was lower than that in the placebo group (no TEA, $1222 \mathrm{ml}$; $p<0.001)$. The transfusion rate was also lower in the one-TEA group $(3.8 \%)$ than in the placebo group $(22 \%$; $p=0.006) \cdot{ }^{[13]}$ Although the current study was retrospective, there were no differences in the study design including patient selection, surgeon, surgical technique, timing and dose of TEA administration, and postoperative care (criteria for transfusion and fluid resuscitation, etc.). Therefore, we consider that our results demonstrate the clinical efficacy of TEA in blood conservation after MIS-TKA when rivaroxaban is administered for thromboprophylaxis.

Despite the efficacy in blood conservation by TEA, there was a higher ecchymosis rate $(41 \%)$ in the study group than in the enoxaparin group $(14 \% ; p=0.001)$. However, the results did not affect the clinical wound-related complications such as hematoma, bullae formation, skin necrosis, or infection, and there was no need to return to OR for open irrigation or debridement in both groups. Although two large clinical trials have shown a similar rate of major bleeding event in patients using rivaroxaban versus enoxaparin after TKA, ${ }^{[6,7]}$ a higher wound complication rate $(3.94 \%)$ in rivaroxaban group compared with a lower rate $(1.8 \%)$ in tinzaparin group after TKA was reported recently. ${ }^{[8]}$ Nevertheless, the minor wound complications such as ecchymosis were not mentioned. The blood conservation effect of TEA in standard TKA was 30-50\%, ${ }^{[10,11]}$ which may explain our results of low postoperative wound-related complications in our series. However, a higher ecchymosis rate in the study group may imply a higher postoperative bleeding than the control group, although total blood loss was not different between the two groups.

Throughout the study period, our team used the same technique as described by Haas et al. ${ }^{[15]}$ to perform the MIS-TKA using the mini-midvastus approach. However, the wound length was shorter in the study group than in the control group $(9.16 \mathrm{~cm}$ vs. $10.3 \mathrm{~cm})$. We consider this to have been caused by the difference in learning curve between the time periods (2009-2011). However, the hospital stay was longer in the study group (5.7 days) than in the control group (5.3 days) ( $p=0.015)$. A higher incidence of ecchymosis around the knee in the study group due to the use of rivaroxaban may have caused temporary discomfort including pain and swelling of the knee, which in turn may have resulted in delayed discharge from the hospital. Nevertheless, all the symptoms and signs subsided 2 weeks after the operation and did not affect the wound healing or caused further wound complications.

We acknowledge the limitations of this study. First, we preoperatively excluded patients with high risk of coagulopathy or thromboembolism. Second, this study was a retrospective review. Further randomized controlled clinical trials are necessary to assess the efficacy and safety of the use of rivaroxaban in clinical practice. In conclusion, our retrospective study demonstrated a low incidence of VTE in MIS-TKA patients who received rivaroxaban or enoxaparin as thromboprophylaxis. No increased perioperative blood loss or postoperative wound-related complications were observed in the rivaroxaban group compared with the enoxaparin group.

\section{Acknowledgment}

We thank MS Ya-Ju Yang for assistance with the statistical design and analysis.

\section{REFERENCES}

1. Clutier JM. Results of total knee arthroplasty with a non-constrained prosthesis. J Bone Joint Surg Am 1983;65:906-19.

2. Ewald FC, Jacobs MA, Miegel RE, Walker PS, Poss R, Sledge CB. Kinematic total knee replacement. J Bone Joint Surg Am 1984;66:1032-40.

3. Brookenthal KR, Freedman KB, Lotke PA, Fitzgerald RH, Lonner JH. A meta-analysis of thromboembolic prophylaxis in total knee arthroplasty. J Arthroplasty 2001;16:293-300.

4. Prevention of venous thromboembolism. International Consensus Statement (Guidelines according to scientific evidence). Int Angiol 1997;16:3-38.

5. Clagett GP, Anderson FA Jr, Geerts W, Heit JA, Knudson M, Lieberman JR, et al. Prevention of venous thromboembolism. Chest 1998;114 (5 Suppl):531-60S.

6. TurpieAG, Lassen MR, Davidson BL, Bauer KA, Gent M, Kwong LM, et al.; RECORD4 Investigators. Rivaroxaban versus enoxaparin for thromboprophylaxis after total knee arthroplasty (RECORD4): A randomized trial. Lancet 2009;373:1673-80.

7. Lassen MR, Ageno W, Borris LC, Lieberman JR, Rosencher N, Bandel TJ, et al.; RECORD3 Investigators. Rivaroxaban versus enoxaparin for thromboprophylaxis after total knee artrhoplasty. N Engl J Med 2008;358;2776-86. 
8. Jensen CD, Steval A, Partington PF, Reed MR, Muller SD. Return to theatre following total hip and knee replacement, before and after the introduction of rivaroxaban A retrospective cohort study. J Bone Joint Surg Br 2011;93:91-5.

9. Galat DD, McGovern SC, Hanssen AD, Larson DR, Harrington JR, Clarke HD. Early return to surgery for evacuation of a postoperative hematoma after primary total knee arthroplasty. J Bone Joint Surg Am 2008;90:2331-6.

10. Benoni G, Fredin H. Fibrinolytic inhibition with tranexamic acid reduces blood loss and blood transfusion after knee arthroplasty: A prospective, randomized, double-blind study of 86 patients. J Bone Joint Surg Br 1996;78:434-40.

11. Hiippala S, Strid L, Wennerstrand M, Arvela V, Mäntylä S, Ylinen J, et al. Tranexamic acid (Cyklokapron) reduces perioperative blood loss associated with total knee arthroplasty. Br J Anaesth 1995;74:534-7.

12. Lin PC, Hsu CH, Chen WS, Wang JW. Does tranexamic acid save blood in minimally invasive total knee arthroplasty? Clin Orthop Relat Res 2011;469:1995-2002.

13. Lin PC, Hsu CH, Huang CC, Chen WS, Wang JW. The blood-saving effect of tranexamic acid in minimally invasive total knee replacement - is an additional preoperative injection effective? J Bone Joint Surg Br 2012;94:932-6.

14. Wang CJ, Wang JW, Weng LH, Hsu CC, Huang CC, Yu PC. Prevention of deep-vein thrombosis after total knee arthroplasty in Asian patients: Comparison of low-molecular-weight heparin and indomethacin. J Bone Joint Surg Am 2004;86:136-40.

15. Haas SB, Cook S, Beksac B. Minimally invasive total knee replacement through a mini midvastus approach. A comparative study. Clin Orthop Relat Res 2004;428:68-73.

16. Nadler SB, Hidalgo JU, Bloch T. Prediction of blood volume in normal human adults. Surgery 1962;51:224-322.
17. Wells PS, Anderson DR, Bormanis J, Guy F, Mitchell M, Gray L, et al. Value of assessment of pretest probability of deep-vein thrombosis in clinical management. Lancet 1997;350:1795-8.

18. Agnelli G, Becattini C. Acute pulmonary embolism. N Engl J Med 2010;363:266-74.

19. Geerts WH, Bergqvist D, Pineo GF, Heit JA, Samama CM, Lassen MR, et al.; American College of Chest Physicians. American College of Chest Physicians: Prevention of venous thromboembolism: American College of Chest Physicians Evidence-Based Clinical Practice Guidelines ( $8^{\text {th }}$ Edition $)$. Chest 2008;133 (6 Suppl):381-453S.

20. Levine MN, Raskob G, Beyth RJ, Kearon C, Schulman S. Hemorrhagic complications of anticoagulant treatment. The $7^{\text {th }}$ ACCP conference on antithrombotic and thrombolytic therapy. Chest 2004; $12: 287$ s.

21. Shaieb MD, Watson BN, Atkinson RE. Bleeding complications with enoxaparin for deep venous thrombosis prophylaxis. J Arthroplasty 1999; 14:432-8.

22. Callaghan JJ, Dorr LD, Engh GA, Hanssen AD, Healy WL, Lachiewicz PF, et al.; American College of Chest Physicians. Prophylaxis for thromboembolic disease. Recommendations from the American College of Chest Physicians- are they appropriate for orthopaedic surgery? J Arthroplasty 2005;20:273-4.

23. Friedman RJ, Gallus AS, Cushner FD, Fitzgerald G, Anderson FA Jr. Physican compliance with guidelines for deep-vein thrombosis prevention in total hip and knee arthroplasty. Curr Med Res Opin 2008;24:87-97.

24. Chung LH, Chen WM, Chen CF, Chen TH, Liu CL. Deep vein thrombosis after total knee arthroplsty in Asian patients without prophylactic anticoagulation. Orthopedics 2011;34:15-20.

25. Lotke PA. Rivaroxaban for thromboprophylaxis. N Engl J Med 2008;359:2174. 